enzyme histochemical, light and electron microscopical findings. $\mathrm{Br} f$ Dermatol 1977;97:267-78.

15 Coskey RJ Eruptive nevi. Arch Dermatol 1975;111:1658.

16 Goldman L, Richfield DF. Effect of corticotrophin and cortisone on the development and progress of pigmented nevi. FAMA 1951;143:941-3.

17 Greene $\mathrm{MH}$, Wilson J. Second cancer following lymphatic and hematopoietic cancers in Connecticut, 1935-82. NCI Monogr 1985;68:191-219.

18 Tucker MA, Meadows AT, Boice JD Jr, et al. Cancer risk following treatment of childhood cancer. In: Boice JD Jr, Fraumeni JF Jr, eds. Radiation carcinogenesis: epidemiology and biological significance. New York: Raven Press, 1984:211-24.

19 Greene $\mathrm{MH}$, Hoover RN, Fraumeni JF Jr. Subsequent cancer in patients with

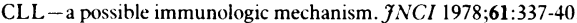

20 Greene MH, Young TI, Clark WH Jr. Malignant melanoma in renal transplant recipients. Lancet 1981;i:1196-8.

21 Tucker MA, Misfeldt D, Coleman CN, et al. Cutaneous malignant melanom following Hodgkin's disease. Ann Intern Med 1985;102:37-41.

22 Swerdlow AJ, English J, MacKie RM, et al. Benign melanocytic naevi as a risk factor for malignant melanoma. Br Med f 1986;292:1555-9.

23 Green A, Maclennan R, Siskind V. Common acquired nevi and the risk of malignant melanoma. Int f Cancer 1985;35:297-300.

24 Allen AC. A reorientation on the histogenesis and clinical significance of cutaneous nevi and melanomas. Cancer 1949;28-41.

(Accepted 12 April 1989)

\title{
Is excessive running predictive of degenerative hip disease? Controlled study of former elite athletes
}

\author{
Bernard Marti, Michael Knobloch, Alois Tschopp, Armin Jucker, Hans Howald
}

Institute of Social and Preventive Medicine, University of Zurich, Zurich, Switzerland Bernard Marti, MD, research fellow

Michael Knobloch, MD, assistant researcher

Alois Tschopp, MSOcsc, research fellow

Department of Radiology, Cantonal Hospital, Schaffhausen, Switzerland Armin Jucker, MD, head of department

Research Institute, Swiss School for Physical

Education and Sports, Magglingen, Switzerland Hans Howald, MD, head

Correspondence to: Dr Bernard Marti, Institute of Social and Preventive Medicine, University of Zurich, CH-8006 Zurich, Switzerland.

BrMed J 1989;299:91-3
Abstract

Objective-To determine the effects of regular long distance running on the state of the hips in later life.

Design-Retrospective study of a cohort of elite athletes and a group of normal, healthy, untrained controls examined 15 years after initial testing.

Setting-Research project at school for physical education and sports.

Subjects -27 Former long distance runners (mean age 42), nine former bobsleigh riders (mean age 42), and 23 normal, healthy, untrained men (mean age 35) who had been examined in 1973 and who agreed to re-examination in 1988.

Main outcome measure-Radiological evidence of degenerative hip disease in 1988.

Results-Physiological and exercise characteristics of all subjects had been recorded in 1973, and in 1988 these measurements were repeated together with radiological examination of the hips. An additive radiological index of hip disease based on grades of subchondral sclerosis, osteophyte formation, and joint space narrowing was significantly increased among runners as compared with bobsleigh riders and untrained controls. After adjustment for age the significant effect of type of sports activity remained $(p=0.032)$. In multivariate analyses age and milage run in $1973(97 \mathrm{~km} /$ week) emerged as independent, significant, and positive predictors of radiological signs of degenerative hip disease in $1988(p=0.017$ and $p=0.024$ respectively $)$. Among runners alone running pace in 1973 rather than milage run was the stronger predictor of subsequent degenerative hip disease. The milage run in 1988 was not particularly predictive of the radiological index, but endurance in 1988 was inversely related to degenerative hip disease seen radiologically.

Conclusion-Long term, high intensity, high milage running should not be dismissed as a potential risk factor for premature osteoarthritis of the hip.

\section{Introduction}

Regular exercise brings several possible health benefits - for example, improved fitness, decreased cardiovascular disease, increased longevity, and emotional wellbeing. ${ }^{1}$ Nevertheless, little information exists about the long term consequences, if any, of exercise on the musculoskeletal system. It has been hypothesised that the repetitive impulse loading of an activity such as habitual running might accelerate the development of degenerative disease in the weight bearing joints. ${ }^{2}$ Indeed, osteoarthritis of the hip was found to be more common in retired football players who had played regularly for more than two decades. On the other hand, a retrospective study of elite athletes found a decreased prevalence of osteoarthritis of the hip among former Finnish champion runners, ${ }^{4}$ and two recent cross sectional investigations failed to identify any significant association between habitual running and premature degenerative disease of the hip. ${ }^{56}$ Recent reviews have therefore concluded that at present there is no convincing evidence that running accelerates the development of osteoarthritis in weight bearing joints. ${ }^{78} \mathrm{We}$ report a controlled retrospective study of the association between running and subsequent degenerative hip disease in a cohort of former elite athletes.

\section{Subjects and methods}

The study sample consisted of the complete Swiss national teams in long distance running (track and field and orienteering) and bobsleigh who had taken part in an exercise test and physical examination at the Swiss School for Physical Education and Sports in 1973. The control group consisted of healthy, untrained men who had volunteered for a randomised training study in 1973 and who had been subjected to the same tests and physical examination protocol as the elite athletes. Of the 27 long distance runners approached, all agreed to take part in the same exercise test and physical examination 15 years later-that is, in 1988; of the 12 bobsleigh riders approached, nine agreed to participate; and of the 26 control subjects approached, 23 agreed to participate (one had died). The total study sample therefore comprised 59 men ( $92 \%$ of those eligible).

Subjects completed a detailed questionnaire on exercise habits, history of sports related injuries, and medical history. In 1988 the subjects also had a rheumatological examination of the legs and an $x$ ray examination of the hips (supine anteroposterior view of pelvis). All radiographs were scored "blind" by an experienced radiologist not associated with the study. Each radiograph was scored for joint space narrowing, subchondral sclerosis, and osteophyte formation. On the films the joint space, expressed as the distance between the ossified surfaces and representing the thickness of the joint cartilage, was measured cranially. Joint space narrowing was classified as grade zero if cartilage thickness was $\geqslant 3 \mathrm{~mm}$, grade 1 if $<3 \mathrm{~mm}$, grade 2 if $<2.5 \mathrm{~mm}$, and grade 3 if $<2 \mathrm{~mm}$. Subchondral sclerosis and osteophyte formation were scored zero (absent) to 3 (excessive) according to standard criteria. ${ }^{9}$ A simple radiological index of degenerative hip disease was then computed by summing the classifications of joint space narrowing, sclerosis, and 
osteophyte formation on each side and presenting the results on ordinal scales. Thus the index range was from zero (absence of radiological signs of degenerative hip disease) to 9. The non-parametric Kruskal-Wallis test and the $\chi^{2}$ statistic were used for unadjusted testing of significance. The effects of the covariates age and milage on the radiological index were tested by analysis of variance and further analysed by multiple linear regression. ${ }^{10}$

\section{Results}

In 1973 all runners trained vigorously, running a mean of $97 \mathrm{~km}$ a week and having a superior endurance capacity (maximum oxygen uptake $73 \mathrm{ml} / \mathrm{kg} \cdot \mathrm{min}$ ). Bobsleigh riders also trained heavily, but more so by means of conditioning exercises and strength training than by running (mean $12 \mathrm{~km}$ a week). Controls were moderately active in 1973, had a slightly above average endurance capacity (maximum oxygen uptake $53 \mathrm{ml}$ kg.min) and were younger (mean age 35 in 1988) than the runners (mean age 42) and bobsleigh riders (42). On clinical examination in 1988 external hip rotation was significantly $(\mathrm{p}<0.05)$ reduced and hip flexion non-significantly reduced in runners and bobsleigh riders as compared with controls.

Table I shows the radiological characteristics of the subjects in 1988. Subchondral sclerosis and osteophyte formation were significantly more prevalent in runners than in controls ( $p<0.001$ and $p<0.05$ respectively) or bobsleigh riders. There was also a tendency towards narrowing of the joint space among runners, who as a group had the thinnest cartilage $(p>0.05)$, and the four subjects with a joint space $<3 \mathrm{~mm}$ were all runners (runners $v$ non-runners, $\mathrm{p}<0 \cdot 05$ ). As a consequence the radiological index of degenerative hip disease was significantly higher in runners than in bobsleigh riders and controls. Five subjects - all runners - satisfied at least two of the radiological criteria for moderate to severe osteoarthritis of the hip-namely, joint space narrowing, subchondral sclerosis grade 2 , osteophyte formation grade 2. Four of them also reported hip pain, which in two cases had forced them to give up running completely and in two others to reduce their running to less than $20 \mathrm{~km}$ a week. The runner with the most severe clinical symptoms of osteoarthritis of the hip, including pain, morning stiffness, and a decreased range of movement, had no radiological joint space narrowing but had severe sclerosis and osteophyte formation. In the fifth case, which was probably due to unilateral epiphysiolysis or Perthes' disease in youth, the subject was free of symptoms and still active but had a decreased range of movement on one side. Generally only runners reported at least occasional definite hip pain (runners $v$ controls, $\mathrm{p}<0.01$ ).

The potential importance of age and intensity of running for the development of degenerative hip disease was further analysed. In correlation analysis of

TABLE I-Radiological findings in hip joint and prevalence of pain in hip

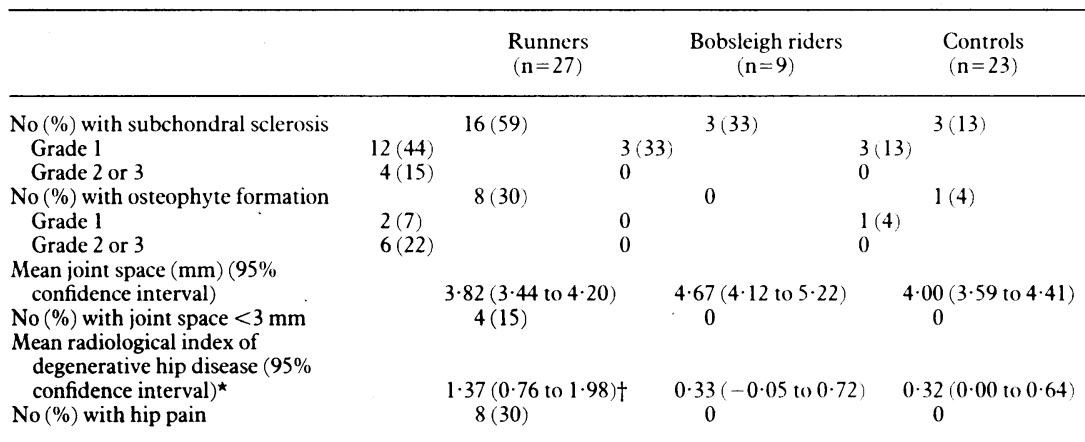

*Additive index of degree of subchondral sclerosis, osteophyte formation, and joint space narrowing.

†Non-parametric analysis of variance (Kruskal-Wallis) of effect of sports activity: $p=0.006$
TABI.E II - Analysis of variance of radiological index of degenerative hip disease stratified by type of sports activity, with age and weekly milage in 1973 as coriariates

\begin{tabular}{lccc}
\hline & $\begin{array}{c}\text { Unadjusted } \\
\text { value }\end{array}$ & $\begin{array}{c}\text { Value adjusted } \\
\text { for age }\end{array}$ & $\begin{array}{c}\text { Value adjusted for } \\
\text { weekly milage in } \\
1973\end{array}$ \\
\hline $\begin{array}{l}\text { Runners } \\
\begin{array}{l}\text { Non-runners (bobsleigh } \\
\text { riders, controls) }\end{array}\end{array}$ & 1.37 & 1.19 & 1.13 \\
\hline & 0.32 & 0.48 & 0.53
\end{tabular}

Analysis with adjustment for age: main effect $=$ type of sports activity, $\mathrm{F}=4,82, \mathrm{p}=0.032 ;$ covariate $=$ age $, \mathrm{F}=13,16, \mathrm{p}=0.001$

Analysis with adjustment for weekly milage in 1973: main effect $=$ type of sports activity, $\mathrm{F}=0,85, \mathrm{p}=0.43$; covariate $=$ weekly milage in 1973 , $\mathrm{F}=11,49, \mathrm{p}=0 \cdot 001$

the whole sample as well as the runners only, age and both milage and running pace were significantly and positively related to the radiological index of degenerative hip disease (data not shown). To control for a possible confounding effect of age we ran an analysis of variance of the radiological index with age as a covariate (table II). The effect of the type of sports activity on the radiological index remained significant $(p=0.032)$. When the main discriminant factor between runners and controls (that is, weekly milage in 1973) was entered as a covariate instead of age this abolished the significant effect of type of sports activity $(p=$ $0 \cdot 43$ ). When the effect of age was controlled for by normalising the radiological index for age (by division through age) the significant effects of sports activity was unchanged in a non-parametric analysis of variance (data not shown).

Multiple regression analyses were performed to estimate the size of the independent contributions of age and running to the radiological index of degenerative hip disease. The impact of age and milage on the index was of similar magnitude, yielding standardised regression coefficients of $0.31 \quad(p=0.017)$ and 0.29 $(p=0.024)$ respectively. In the regression of the radiological index among runners alone the average running pace in 1973 emerged as a better predictor than milage in 1973. When the set of potential predictor variables from 1988, including lifetime milage, was added to the model with the 1973 variables and then submitted to stepwise backward regression of the radiological index all the 1988 variables were eliminated from the model with the exception of endurance capacity. Interestingly, this last was inversely related to degenerative hip disease, which points to the possibility of a "healthy runner effect" in barely cross sectional analysis.

\section{Discussion}

In this small observational study a history of regular, vigorous, and high milage long distance running was found to be a significant predictor of degenerative hip disease in later life as detected radiologically. Statistically, the magnitude of this effect was comparable to that of age as a risk factor for osteoarthritis. " Our observation is at variance with recent reviews ${ }^{7 \times}$ concerned principally with four studies ${ }^{4-612}$ that did not find any precipitating effect of running on degenerative joint disease.

There are several possible explanations for the negative results of other studies. The Finnish study for example, had a design similar to ours but assessed the effect of competitive running as usually conducted between 1930 and $1960 .{ }^{4}$ Almost certainly during the period of our study (the 'seventies and 'eighties) elite endurance athletes ran substantially further, sustaining much greater long term physical impact on weight bearing joints. The two most recent cross sectional studies $^{56}$ may have been biased by a "healthy runner effect, "1:14 the classification of runners and non-runners being based on actual activity and recall, not on a baseline assessment of intensity of activity and subsequent 
follow up. The runners investigated by Lane $e t a l^{5}$ and Panush et $a l^{6}$ had been running for a shorter period than those in our study (mean number of years of regular running $19 \cdot 7$ (95\% confidence interval 10.6 to $28 \cdot 8)$ ). Finally, a large retrospective study ${ }^{12}$ did not assess joint state radiologically, which in the light of our findings seems mandatory.

Plainly our study also had limitations. Firstly, no $x$ ray pictures were taken at baseline in 1973, so that the progression of radiological signs of osteoarthritis over time could only be assumed. Secondly, the two reference groups included as controls did not match perfectly with the group of runners - for example, the untrained controls were significantly younger than the elite athletes, which meant making statistical adjustment for the confounding effect of age. As in both the analysis of variance and the multiple regression analyses the independent predictive power of running in 1973 for the radiological state of the hips in 1988 was statistically confirmed in the presence of age, we believe that our findings are reasonably strong evidence that excessive running is a potential risk factor for degenerative hip disease in later life. Thirdly, no information is available on the radiological or clinical prevalence of osteoarthritis of the hip in the Swiss population at large, so that we do not know whether the prevalence found in our series was normal, high, or low. We also emphasise the weak association found between radiological signs and reported symptoms; of the 24 subjects showing radiological evidence of degenerative hip disease, only six reported at least occasional definite hip pain.

A characteristic of the radiological signs in the hips of our runners was that they corresponded more to the hypertrophic than to the destructive type of osteoarthritis, which may be typical in physically highly active, moderately young people. " Increased reactive bone formation has been interpreted as a good bone response to mechanical overload, ${ }^{15}$ and some workers suggest that the bony remodelling seen in runners without joint space narrowing may protect the cartilage from wear and tear. ${ }^{5}$ The relevance of reactive bone formation such as subchondral sclerosis, however, is still unclear. Bone remodelling might also be viewed as a more than appropriate response of bone tissue to the trabecular microfractures caused by repetitive impulse loading, and subchondral sclerosis may therefore represent a radiological sign of bone stiffening, which in turn will increase stress on articular cartilage and thus precipitate breakdown of cartilage.

Of the two variables determining the effects of long term endurance running, interestingly pace tended to be more predictive of radiological signs of degenerative hip disease than milage among runners alone. Hypothetically, muscles fatigued by a combination of long distance and fast running pace will have less ability to absorb shock transmitted to the skeleton, which over years of such activity might lead to increased wear and tear in weight bearing joints. Hence it seems reasonable to assume that in elite runners abnormally intense stresses are imposed on joint cartilage with probably normal biomaterial properties. ${ }^{15}{ }^{16}$ Plainly a significant increase in the average risk of degenerative hip disease in regular runners does not mean that even excessive milage will inevitably lead to osteoarthritis; of the three runners in our series with the highest lifetime milage (average $133500 \mathrm{~km}$ ), only one had some radiological evidence of degenerative hip disease, which may have been due either to individual random variability or to selection.

In this study early radiological signs of degenerative hip disease were found in runners with extremely high milage. Hence, the public health importance of osteoarthritis of the hip induced by running may be minimal, given the small section of the population at risk. Nevertheless, until more is known reports emphasising the joint protective properties of running? should be regarded with caution. In 1975 Puranen et al thought that their study "excluded the possibility that the physical strain to which runners' hips are exposed would contribute to its (osteoarthritis) development." We, however, think that long term, high intensity, high milage running as performed by elite endurance athletes during the 'sixties and 'seventies should not be dismissed as a potential risk factor or at least precipitating factor for premature osteoarthritis of the hip.

This study was supported by a grant from Eidgenössische Turn-und Sportkommission. We thank the Swiss National Research Foundation for grant No 3.763-0.87 to BM, and Dr Edgar Stuessi, of Zurich, and Dr Urho Kujala, of Turku, Finland, for valuable comments.

1 Powell KE, Paffenbarger RS. Workshop on epidemiologic and public health aspects of physical activity and excercise: a summary. Public Health Rep 1985;100:118-26.

2 Radin EL, Paul IL, Rose RM. Role of mechanical factors in pathogenesis of primary osteoarthritis. Lancet 1972;i:519-22.

3 Klünder KB, Rud B, Hansen J. Osteoarthritis of the hip and knee joint in retired football players. Acta Orthop Scand 1980;51:925-7.

+ Puranen J, Ala-Ketola L, Peltokallio P, Saarela J. Running and primary osteoarthritis of the hip. Br Med f 1975;ii:424-5.

5 Lane NE, Bloch DA, Jones HH, Marshall WH Jr, Wood PD, Fries JF. Longdistance running, bone density and osteoarthritis. $\mathcal{F A M A}$ 1986;255:114751.

6 Panush RS, Schmidt $C$, Caldwell JR. Is running associated with degenerative joint disease? FAMA 1986;255:1152-4.

Burry HC Sport exercise and arthritis. Br f Rheumatol 1987;26:386-8.

8 Lane NE, Fries JF. Relationship of running to osteoarthritis and bone density. Compr Ther 1988;14:7-15.

9 Weiss K. Degenerative Gelenkerkrankungen. In: Diethelm L et al, eds. Handbuch der medizinischen Radiologie. Röntgendiagnostik der Skeletterkrankungen. Vol 5. Pt 3. Berlin, Heidelberg, New York: Springer, 1968;543 602 .

10 Nie NH. SPSSX user's guide. Ist ed. New York: McGraw-Hill, 1983.

11 Typpo $T$. Osteoarthritis of the hip. Radiologic findings and etiology. Ann Chir Gynaecol 1985;74(suppl 201):1-37.

12 Sohn RS, Micheli LJ. The effect of running on the pathogenesis of osteoarthritis of the hips and knees. Clin Orthop 1985;198:106-9.

Murphy WA. The relation of running to bone and joint disease. $7 A M A$ 1986;256:715.

4 Dwyer 256.7 Fitness programmes and musculoskeletal status. Med 7 Aust 1988 : 148.378-9.

15 Sot 14.37 . behind the disease Am Rheum Dis 1982;41:118-25.

16 Solomon L. Patterns of osteoarthritis of the hip. I Bone foin Surg 1976; $58 \mathrm{~B}: 176-83$.

(Accepted 14 April 1989)

\section{ONE HUNDRED YEARS AGO}

An unpleasant circumstance has arisen at the North Dublin Union, which has served to bring into public prominence the method of supplying subjects to the medical schools. It appears that a man sent his mother into the workhouse hospital, where she died; and he only heard of the fact some days afterwards in an accidental way. He applied at the workhouse, and found that the body had been removed to a medical school, as unclaimed. It appeared, upon investigation, that an effort had been made to find the deceased's former residence, but had failed. Some guardians learned that the resident medical officer and the gate-porter received fees in connection with the transfer of bodies, and denounced this as a traffic in human flesh. But these fees are paid for the signing of necessary certificates, and for extra work done by the porter. An investigation is being held into the whole matter. Every care should be taken to see that the provisions of the Act are properly observed; a noisy guardian can, however, awaken some public sentiment in a matter of this kind. But a little common sense must show that the error in this case was accidental, and in the present case we are glad to say the body was recovered without having been disfigured. (British Medical Fournal 1889;i:793) 